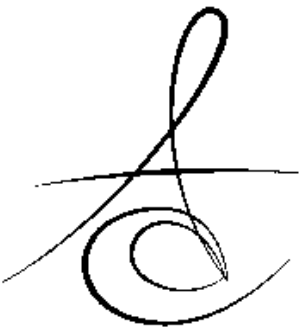

\title{
İZMİR İLİNDEKİ 6 YAŞ GRUBU ÇOCUKLARIN AĞIZ-Dİş SAĞLIĞI DURUMLARININ DEĞERLENDİRİLMESİ VE ÖNEMLİ ÇÜRÜK İNDEKSİNİN ÖNEMİ
}

\section{THE EVALUATION OF ORAL HEALTH STATUS OF 6-YEAR-OLD CHILDREN IN IZMIR AND SIGNIFICANCE OF THE SIGNIFICANT CARIES INDEX}

\author{
Dr. Öğr. Üyesi Berna KUTER*
}

Makale Kodu/Article code: 3672

Makale Gönderilme tarihi: 18.05 .2018

Kabul Tarihi: 26.06 .2018

\section{öz}

Amaç: Çalışmamızın amacı İzmir'deki 6 yaş çocuklarının ağız diş sağlığının def-t, df-t, def-s, DMF-T indeksi ile değerlendirmek, Önemli Çürük İndeks (SiC) ile çürük riski yüksek bireylere dikkati çekmek ve ayrıca çürük prevalans hızını belirlemektir.

Gereç ve Yöntem: Çalışmamızda 6 yaşındaki 396 kız, 367 erkek 763 çocuğun Dünya Sağlık Örgütü standartlarına göre ağız içi muayeneleri yapılmıştır. Çocukların süt dişlerinde def-t indeks (d:çürük, e:çürük nedeniyle kaybedilmiş, f:dolgulu dişler, t:diş), df-t indeks (d: çürük, f:dolgulu dişler), def-s indeks (d:çürük, e:çürük nedeniyle kaybedilmiş, f:dolgulu dişler s:yüzey), daimi dişlerinde DMF-T indeks (D:çürük, M:kaybedilmiş, F:dolgulu dişler, T:diş) ve SiC çürük indeks ile çürük durumu değerlendirilmiş, ayrıca çürük prevalans hızı hesaplanmıştır.

Bulgular: Çocuklarda süt dişlerinde def-t çürük indeks değeri 5.1389, df-t çürük indeks değeri 4.4678, def-s çürük indeks değeri 8.3277, DMF-T çürük indeks değeri 0.1455, deft(SiC) çürük indeks değeri 9.2519 ve çürük prevalans hızı \%86.63 olarak tespit edilmiştir. Kız ve erkek çocukları arasında istatistiksel olarak anlamlı bir fark gözlenmemiştir.

Sonuç: Yapılan çalışmada, SiC çürük indeks değerinin yüksek çürük prevalansına sahip çocuklara dikkati çekmesi nedeniyle def-t çürük indeks değerine göre yüksek olduğu sonucuna varılmıştır. İzmir'de ağız sağlığı eğitim programlarına intiyaç olduğu ve SiC çürük indeksinin def-t ve DMF-T çürük indeks ile birlikte çocuklardaki diş çürüklerinin değerlendirilmesinde yararlı olduğu düşünülmektedir.

Anahtar Kelimeler: Süt dişleri, diş çürüğü, DMF indeksleri

\begin{abstract}
Aim: The aim of this study was to evaluate def-t, df-t, def-s, DMF-T of children aged 6 years in Izmir, to bring attention to children with the highest caries values with the significant caries index and also to determine caries prevalence rate.
\end{abstract}

Material and Methods: Intraoral examinations were carried out according to World Health Organization inspection standards. 763 children's (396 girls, 367 boys) def-t index (d:decayed, e:extracted due to caries, f:filled, t:teeth for primary dentition), df-t index (d:decayed, f:filled), def-s index (d:decayed, e:extracted due to caries, f:filled s:surfaces for primary dentition), DMF-T index (D:Decayed, M:Missed, F:Filled T:Teeth for permanent dentition), Significant Caries Index (SiC) and caries prevalence rate were evaluated.

Results: The def-t index were found as 5.1389, df-t index were 4.4678, def-s index were 8.3277, deft(SiC) index were found 9.2519 and caries prevalance rate in primary teeth of children was obtained as \%86.63. The difference between girls and boys was not statistically significant.

Conclusions: It has been concluded that SiC index was higher than def-t index, owing to bring attention to children with the highest caries values, in this study. Oral health education programs are needed in Izmir and it has been thought that the SiC index is very useful index in the evaluation of the dental caries experience along with the def-t and DMF-T indices.

Keywords: Primary teeth, dental caries, DMF indices

*İzmir Demokrasi Üniversitesi, Diş Hekimliği Fakültesi, Pedodonti A.D, İzmir 


\section{GİRİş}

Çocuklarda ağız diş sağlığının geliştirilebilmesi için öncelikle hedef kitlenin belirlenmesi, sonrasında çürük durumunun saptanması ve önlenmesine yönelik koruyucu tedbirlerin alınması sağlanmalıdır. ${ }^{1}$ Türkiye'de ağız diş sağlığını gösteren ilk çalışma 1988 yılında yapılmış, Dünya Sağlık Örgütünün (DSÖ) 1987 ölçütlerine göre diş çürüğü prevalansı ve tedavi gereksinimlerinin değerlendirilmesi amaçlanmıştır. Birçok ülkede bir halk sağlığı sorunu olan diş çürükleri ve buna bağlı oluşan çürük prevalansı, 1980'li yıllarda gelişmiş ülkelerde, özellikle çocuk populasyonunda hızla düşüşe geçmektedir., ${ }^{2,3}$ Koruyucu hekimlik hizmetlerinin yaygınlaştırıması ve eğitim faaliyetlerinin artması ile birlikte, özellikle son yıllarda, ülkemizde çocukların diş çürüğü prevalansında azalma olması beklenmektedir. Çocukların ağız sağlığına ilişkin ölçütlerin hesaplanmasında DSÖ'nün standart sistemlerinin kullanılması önerilmektedir. ${ }^{4} \mathrm{Bu}$ ölçütler hem tedavi planlamasında hem de koruyucu hizmetlerin başarılı olmasında etkilidirler. Epidemiyolojik verilerin toplanmasının önemli olduğunu belirten DSÖ, toplumdaki diş çürüğü ölçümü ve karşılaştırması için DMF-T (Decayed Missed Filled Teeth, çürük, kaybedilmiş, dolgulu dişler) ve DMF-S (Decayed Missed Filled Tooth Surface, çürük, çürük nedeniyle kaybedilmiş, dolgulu diş yüzeyleri) çürük indekslerinin kullanımını tavsiye etmektedir. ${ }^{5,6}$ Süt dişleri için bu indeks def-t ve def-s çürük indeksi olarak düzenlenmiş ve 6 yaş, süt dişlerindeki çürük düzeyini belirlemesi açısından önemli bir yaş olarak bildirilmiştir. Yapılan çalışmalarda, DMF-T ve def-t indeks değerlerinin bazı popülasyonlarda çürük indeks değeri çok yüksek olan bireyleri doğru yansıtmadığı belirtilmiştir. ${ }^{7,8} \mathrm{SiC}$ çürük indeks her popülasyondaki en yüksek çürük değerine sahip bireylere dikkati çekmek üzere planlanmıştır ve popülasyonun çürüğe en yatkın 1/3'lük bölümünde istatistiksel değerlendirme yapmaktadır. ${ }^{9}$ Çürük prevalansının düşük olduğu durumlarda ortalama DMF-T, SiC çürük indeks değerinden daha çok hataya neden olmaktadır. ${ }^{9,10} \mathrm{Bu}$ nedenle SiC çürük indeks, yüksek çürük prevalansına sahip bireylerin daha iyi değerlendirilmesini sağlamaktadır. Ülkemizde bu indeksle yapılmış, özellikle çocuklara yönelik çok az sayıda çalışma bulunmaktadır. ${ }^{11} \mathrm{Bu}$ çalışmanın amacı, DSÖ kriterlerine göre belli standartlara göre ağız muayeneleri yapılan 6 yaşındaki çocukların ağız ve diş sağlığını değerlendirerek, çürük prevalanslarının tespiti, def-t, df-t, def-s, DMF-T ve SiC çürük indeks değerlerinin hesaplanması, her iki indekse göre elde edilen değerlerinin karşılaştırılması ve çalışmalarda özellikle çürük riski yüksek bireylere dikkat çekilmesinin sağlanmasıdır.

\section{GEREÇ VE YÖNTEM}

$\mathrm{Bu}$ çalışmada İzmir şehir merkezinde Konak merkez ilçesinde 6 ilkokulda, 1.sınıfta öğrenim gören 6 yaşındaki 396 kız, 367 erkek olmak üzere toplam 763 çocuğun ağız diş muayeneleri yapılmıştır. İlçe merkezinde, sosyoekonomik durumu düşük ailelerin yaşadığı, homojen sosyodemografik yapıdaki devlet ilköğretim okullarında öğrenim gören çocukların diş muayeneleri yapılmıştır. Tüm değerlendirmeler hazırlanan muayene formuna kaydedilmiştir. Çocukların diş muayeneleri DSÖ kriterleri göz önünde bulundurularak ayna ve muayene sondu ile gün ışığında ve okul ortamında yapılmıştır. Yapılacak muayeneler ile ilgili olarak İzmir Valiliği İzmir İl Milli Eğitim Müdürlüğüne bağlı Konak İlçe Milli Eğitim Müdürlüğünden, İzmir İl Sağlık Müdürlüğü İzmir Eğitim Diş Hastanesi Başhekimliğinden ve muayene edilecek çocukların velilerinden yazılı onay alınmıştır. Yapılan çalışmada kız ve erkek çocuklar için ayrı ve toplam def-t, def-s, df-t, DMF-T çürük indeksi, deft(SiC) ve def-s(SiC) çürük indeks değerleri belirlenmiş, ayrıca çürük prevalans hızı tespit edilmiştir. Çalışmaların bir kısmı def-t bir kısmı df-t çürük indeksi şeklinde bildirildiğinden, her iki çürük indeks ile her iki grup ile değerlendirme yapılmıştır. 6 yaş I. azı dişlerin sürdüğü yaş olması nedeniyle DMF-T çürük indeks değeri de hesaplanmıştır. SiC çürük indeks değeri hesaplanması aşağıdaki şekildedir.

a. Çocukların def-t değeri bulunur

b. Değerlendirilen grubun en yüksek def-t indeks değerine sahip $1 / 3$ bireyleri seçilir

c. Seçilen alt grup için def-t indeks değeri SiC çürük indeks değerini verir. ${ }^{9}$

SiC çürük indeks değeri Excel programında geliştirilmiş uygulama da def-t indeks verilerinin girilmesi ile de hesaplanabilmektedir. ${ }^{9} \mathrm{SiC}$ çürük indeks değeri hem def-t ve hem def-s çürük indeks değerleri ile hesaplanabilinmektedir. Çocukların cinsiyete göre def-t çürük indeks değerleri arasında farklılık olup olmadığı Two -Independent Sample T-Test ile değerlendirilip, istatistiksel değerlendirme SPSS 22 (SPSSInc, ChicagoUSA) programında gerçekleştirilmiştir.

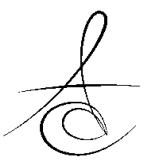




\section{BULGULAR}

İzmir ili Konak merkez ilçesinde sosyoekonomik durumu düşük ailelerin yaşadığı bölgede, ağız ve diş sağlığı durumu incelenen 6 yaşındaki, 763 ilkokul öğrencisinin def-t, df-t, def-s, DMF-T, deft(SiC) ve defs(SiC) çürük indeks değerleri ile çürük prevalans hızı sonuçları Tablo 1'de verilmiştir. Kız ve erkek çocukların dağılımı açısından istatistiksel olarak anlamlı bir fark saptanmamıştır. Populasyonun kız ve erkek çocuklar arasında def-t, df-t, def-s, DMF-T, deft(SiC) ve defs(SiC) çürük indeks değerlerinde istatistiksel olarak anlamlı bir fark gözlenmemiştir (Tablo 1). Tüm popülasyonun çürük prevalans hızı \%86.63, kız çocuklarının çürük prevalansı hızı \%85.73, erkek çocukların çürük prevalansı hızı $\% 87.44$ olarak bulunmuştur.

Tablo 1. Tüm popülasyonun farklı çürük indeks değerleri

\begin{tabular}{|c|c|c|c|}
\hline \multirow[b]{2}{*}{ İndeksler } & \multicolumn{2}{|c|}{ Cinsiyet } & \multirow[b]{2}{*}{ Toplam } \\
\hline & $\mathbf{K} \mathbf{\prime z}$ & Erkek & \\
\hline def-t \pm SD & $5,0336 \pm 3,0926$ & $5,2359 \pm 3,0967$ & $5,1389 \pm 6,8600$ \\
\hline df-t土SD & $4,7549 \pm 3,5122$ & $5,3928 \pm 3,4687$ & $4,4678 \pm 6,8667$ \\
\hline def-s \pm SD & $8,2611 \pm 6,0675$ & $8,4725 \pm 5,5634$ & $8,3277 \pm 5,3456$ \\
\hline DMF-T \pm SD & $0,1618 \pm 0,3041$ & $0,1287 \pm 0,2947$ & $0,1455 \pm 0,2996$ \\
\hline deft(SiC) & 9,1839 & 9,3790 & 9,2519 \\
\hline defs(SiC) & 18,4125 & 16,4743 & 17,4746 \\
\hline $\begin{array}{c}\text { Çürük } \\
\text { Prevalansı Hızı }\end{array}$ & $\% 85,73$ & $\% 87,44$ & $\% 86,63$ \\
\hline
\end{tabular}

\section{TARTIŞMA}

Epidemiyolojik çalışmalar toplumların ağız ve diş sağlığı profillerinin belirlenmesinde önemli bir yer tutmaktadır. ${ }^{12}$ Çocukların mümkün olan en küçük yaşta diş bakımına başlamaları çürük oluşumunun önlenmesinde oldukça önemlidir. ${ }^{13}$ Çalışmamızda 6 yaş çocukları için def-t çürük indeks değeri 5.13 bulunurken, Yıldız ve arkadaşları 5.00, Gökalp ve arkadaşları 5 yaş çocukları için 3.70, Güler ve arkadaşları 7-12 yaş aralığında 2.38, Kemaloğlu ve arkadaşları 712 yaş aralığında 2.38, Kapdan ve arkadaşları 6 yaş için df-t çürük indeks değerini 3.64, Eronat ve arkadaşları 5-7 yaş aralığında 2.78, Öztunç ve arkadaşları 6 yaş için 3.74-2.53, Liompart ve arkadaşları 4.64, Wei ve arkadaşları 3,2, değerini bulmuşlardır. ${ }^{12,14-21}$ Saydam ve arkadaşlarının 5.15 df-t çürük indeks değeri yapılan çalışmaya göre daha yüksek bulunurken, İzmir Konak bölgesi için bulunan 4,46 df-t çürük indeks değeri Eronat ve arkadaşlarının İzmir Bornova için bildirdikleri $4.45 \mathrm{df}$-t çürük indeks değerine yakın saptanmıştır. ${ }^{22,23}$ Yine yapılan çalışmada bildirilen 8.32 def-s çürük indeks değeri, Kuvvetli ve arkadaşlarının bulduğu 1.93 ve 2.47 değerlerine göre yüksek, Şengül ve arkadaşlarının 9,41 def-s çürük indeks değeri ile Liompart ve arkadaşlarının çalışmasındaki 9.02 çürük indeks değerine göre düşük bulunmuştur. ${ }^{11,20,24}$ Öztunç ve arkadaşları çocuklarda 6 yaşında çürük nedeniyle tedavi ihtiyacının başladığını bildirirken, Kapdan ve arkadaşları çalışmalarında 3 yaşa göre 6 yaş çocuklarında df-t çürük indeks değerinde anlamlı bir artış saptadıklarını ve çürük oranının yaşla birlikte arttığını bildirmişlerdir. ${ }^{17,19}$ Yapılan çalışmada 6 yaş için bulunan çürük indeks değerinin yüksek olması ve Eronat ve arkadaşlarının yine İzmir için buldukları çürük indeks değerinin çalışmamızla benzer olması Öztunç, Kapdan ve arkadaşlarının tespitini desteklemektedir. ${ }^{17-19}$ DSÖ daimi dişlerin sürmeye başladığı 6 yaşı, çocuklarının ağız diş sağlığının değerlendirilmesinde kriter yaşlardan biri olarak belirlediğinden, çalışma grubu 6 yaş olarak belirlenmiştir. ${ }^{4} 6$ yaş kız çocuklarında Şengül ve arkadaşları def-s çürük indeks değerini 9,14 bulurken yapılan çalışmada daha düşük olarak 8,26 def-s tespit edilmiştir. ${ }^{11}$ Liompart ve arkadaşları kız çocuklarında aynı yaş grubunda e çekilmiş diş faktörünü dahil etmeden yaptıkları çalışmada df-s çürük indeks değerini 9,27 olarak bildirmişlerdir. ${ }^{20}$ Kapdan ve arkadaşları en fazla çürük indeks değerinin 6 yaş grubunda görüldüğünü, diğer yaşlar arasında bir fark tespit etmediklerini bildirmişlerdir. ${ }^{17}$ Erkek çocuklarda def-s indeks değeri Şengül ve arkadaşları 9,62, yapılan çalışmada 8,47, Liompart ve arkadaşları df-s indeks değeri 8,78 olarak bildirilmişdir. ${ }^{11,20}$ Süt dişlerine yönelik SiC çürük indeksi ile yapılmış çok az sayıda çalışma bulunmaktadır ve çoğunlukla daimi dişlenme ile ilgilenilmiştir. Namal ve arkadaşlarının yaptığı çalışmada 5-6 yaş çocuklarında def-t çürük indeks değeri 3.74, aynı grup çocuk için SiC çürük indeks değeri 7.75, Şengül ve arkadaşları 6 yaş çocuklarında def-t çürük indeks değeri 4.44, SiC çürük indeks değeri 9.14 olarak, yaklaşık iki kat yüksek bir değer bildirmişlerdir. ${ }^{11-25}$ Yapılan çalışmada Şengül ve arkadaşlarında olduğu gibi benzer bir şekilde def-t çürük indeks değeri 5.13 bulunurken, SiC çürük indeks değeri 9.25 olarak tespit edilmiştir. ${ }^{11}$ Aynı popülasyonun çürük durumunu saptayan her iki indeks

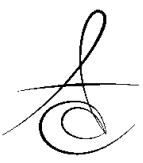


arasındaki bu yüksek farkın nedeni SiC çürük indeks değeri hesaplanmasında çürük sayısı en yüksek bireylerin değerlendirmeye alınmasıdır. ${ }^{9}$ DMF-T ve deft çürük indeksleri, düşük, orta ve yüksek çürük prevalansına sahip çocukların aynı popülasyonda homojen olarak bulunduğu durumlarda güvenilirken, çok yüksek ve çok düşük değerde çürükleri olan toplulukların değerlendirilmesinde yanılma payı fazla olmaktadır. ${ }^{7}$ Yapılan çalışmada def-t ile deft(SiC) çürük indeks değerleri arasındaki fark, değerlendirilmeye alınan popülasyonda hem çok yüksek hem de çok düşük çürük indeks değerlerine sahip bireyler olduğunu ve yüksek çürük prevalansına sahip birey sayısının yüksek olduğunu göstermektedir. Aynı popülasyonda çürük prevalansı $\% 86,63$ olarak tespit edilirken, Şengül ve arkadaşları \%76,58, Kapdan ve arkadaşları \%70, Liompart ve arkadaşları $\% 67,7$ olarak bildirmişlerdir. ${ }^{11,17,20}$ Diğer çalışmalarda farkı bölgelerin farkı sosyoekonomik düzeydeki çocuklarında değerlendirilme yapilırken, yapılan çalışmada sadece düşük sosyoekonomik düzeydeki aynı bölgede yaşayan aynı yaştaki çocukların çürük prevalansının değerlendirilmesi nedeniyle, diğer çalışmalara göre daha yüksek çürük prevalansı saptandığı düşünülmektedir. Hjern ve arkadaşları ve Thomson ve arkadaşları yüksek riskli bireylerin bir şehrin belirli bir bölümünde yaşadıklarını ve belirli bir sosyoekonomik düzeyin altında yaşayan bireylerin daha çok çürük oluşumuna eğilimli olduklarını bildirmişlerdir. ${ }^{26,27}$ Bu durum yapılan çalışmamızda bulunan yüksek çürük prevalansını ve yüksek SiC çürük indeks değerini açıklamaktadır. Mothupi ve arkadaşları def-t çürük indeks değerini 2.3 olarak bildirirken aynı popülasyonda SiC çürük indeks değeri 6.41 olarak saptamışırı. ${ }^{28}$ Mothupi'nin çalışmasında SiC çürük indeks değerinin def-t çürük indeks değerine göre yaklaşık 3 kat fazla bir değer bulunması grup içinde homojen bir çürük dağılımı olmadığını, çok yüksek ve çok düşük çürük değerlerine sahip bireyler olduğunu göstermektedir. Yapılan çalışmalarda DMF-T indeks değerlerinde de benzer farklılıklar bildirilmiş, Marthaler ve arkadaşları DMF-T ve SiC indeks değerlerini sırasıyla 0.90 ve 2.46 , Calado ve arkadaşları 2.51 ve 2.68, Giacaman ve arkadaşları kırsal bölgede 3.36 ve 6.21 , kentsel bölgede 2.29 ve 4.71 , Ferrazzano ve arkadaşları 1.17 ve 3.42 , Campus ve arkadaşları SiC çürük indeks değerini 5.5, Nishi ve arkadaşları DMF-T değerlerini 14 ülke için 1.0 ile 8.5 , SiC çürük indeks değerlerini 2.8 ile 13.7 aralığında olduğunu bildir- mişlerdir. ${ }^{29-34}$ Marthaler ve arkadaşları çürük durumunun tespitinde SiC çürük indeks kullanımının yararlı olduğunu ve SiC indeks değerlerinin azalmasının yüksek çürük risk grubundaki çocukların çürük değerlerinde azalmanın sonucu olduğunu belirtmişlerdir. ${ }^{29} \mathrm{SiC}$ indeks yüksek çürük prevalansına sahip bireylere dikkati çektiği için, def-t ve DMF-T indekslerine göre hata payı daha düşük olmaktadır., ${ }^{9,33}$ Populasyonun kontrol altında olduğu düşünülen düşük def-t çürük indeks değerinde aslında hala yüksek çürük prevalansına sahip birçok birey bulunduğu bu indeks hesaplanmasında gözden kaçabilmektedir. ${ }^{7,34} \mathrm{SiC}$ indeks yüksek çürük prevalansına sahip çocukların değerlendirilmesine imkan vermektedir. ${ }^{25}$ Ayrıca program kullanımının basit ve kolay olması nedeniyle uzman olmayan kişiler tarafından da verilerin girilmesi ile hesaplanabilmektedir. SiC indeksin epidemiyolojik çalışmalarda DMF-T ve def-t indeksleriyle birlikte kullanımasının gelecekteki çalışmalarda oldukça faydalı olacağı bildirilmektedir. ${ }^{9,10,25}$

\section{SONUÇ}

İzmir merkezinde yürüttüğümüz bu çalışmada, çürük riski yüksek bireylerin günümüzde de yüksek seviyede olduğu ve daha geniş kapsamlı epidemiyolojik çalışmaların yapılması gerektiği sonucuna varımıştır. SiC çürük indeksinin çocuklara yönelik gelecekteki çalışmalarda kullanılmasının ve çocuklarda çürük oluşumunun azaltılabilmesinde ağız diş sağlığı eğitimleri ile koruyucu hekimlik hizmetlerinin yaygınlaştırımasının önemli olduğu düşünülmektedir.

Berna Kuter: ORCID ID: 0000-0002-1234-8237

\section{KAYNAKLAR}

1. Saydam G, Oktay İ, Möller İ. Turkiyede ağız diş sağlığı durum analizi. Dünya Sağık Örgütü Avrupa Bölgesi-Sağlık Bakanlığı, Ankara, 1990.

2. Suni $J$, Helenius $H$, Alanen P. Tooth and tooth surface survival rates in birth cohorts from 1965, 1970, 1975 and 1980 in Lahti, Finland. Community Dent Oral Epidemiol 1998; 26: 101-6.

3. Zerwski M, Koch MJ, Niekush U, State HJ. Caries prevalance and treatment needs of 7-to10-yearold schoolchildren in Southwestern Germany. Community Dent Oral Epidemiol 1997;25:348-51. 
4. WHO Oral Health Surveys-Basic Methods. 4th Edition. World Health Organization, Geneva 1997.

5. Aggerryd T. Goals for oral health in the year 2000: cooperation between WHO, FDI and the National Dental Association. Int Dent J 1983; 33: 55-9.

6. Oral health surveys: basic methods. 3rd ed. Geneva: Word Health Organization, 1987.

7. Burt BA. Prevention policies in the light of the changed distribution of dental caries. Acta Odontol Scand 1998;56:179-86.

8. Pitts NB. Do we understand which children need and get appropriate dental care? Br Dent J 1997; 182: 273-8.

9. Bratthall D. Introducing the Significant Caries Index together with a proposal for a new global oral health goal for 12-year-olds. Int Dent J 2000; 50:378-84.

10. Campus G, Solinas G,Maida C, Castiglia P. The Significant Caries Index (SiC): a critical approach. Oral Health Prev Dent 2003; 3: 171-8.

11. Şengül $F$, Derelioğlu $S$, Yıldırım $M$, Demirci $T$, Çelik $P$, Çoruh M. Erzurum ilinde 4-6 yaş grubu çocuklarda oral sağlık durumunun gözden geçirilmesi. Atatürk Üniv Diş Hek Fak Derg 2013; 21: 153-8.

12. Kemaloğlu $H$, Yıldırım K, Kaya A, Önal B. İzmir ilinin Seferihisar ilçesindeki 8-12 ve 13-16 yaş aralığındaki çocuklarda çürük dağılımının değerlendirilmesi. Atatürk Üniv Diş Hek Fak Derg 2014; 24:353-9.

13. Gökalp S, Doğan BG, Tekçiçek M, Berberoğlu A, Ünlüer Ş. Beş, on iki ve on beş yaş çocuklarının ağız diş sağlığı profili, Türkiye-2004. Hacettepe Diş Hek Fak Derg 2007;31:3-10.

14. Yıldız E, Şimşek M, Gündoğar Z, Aktan AM. Oral health survey of children referring to faculty of dentistry in Gaziantep. Gaziantep Med J 2015; 21: 118-124.

15. Gökalp S, Doğan BG, Tekçiçek M, Berberoğlu A, Ünlüer Ş. National survey of oral health status of children and adults in Turkey. Community Dental Health 2010;20:1-6.

16. Güler Ç, Eltas A, Güneş D, Görgen VA, Ersöz M. Malatya ilindeki 7-14 yaş arası çocukların ağız-diş sağlığının değerlendirilmesi. İnönü Üniv Sağlık Bilimleri Derg 2012;2:19-24.
17. Kapdan A, Kuştarcı A, Kapdan A, Buldur B, Arslan D. Sivas ilindeki okul öncesi yaş grubu çocukların diş sağlığı durumlarının değerlendirilmesi. Cumhuriyet Dent J 2010;13:91-5.

18. Eronat N, Koparal E. Dental caries prevalance, dietary habits, tooth-brushing and mother's education in 500 urban turkish children. J Marmara Univ Dent Fac 1997;2:599-604.

19. Öztunç $H$, Haytaç MC, Özmeriç N, Uzel İ. Adana ilinde 6-11 yaş grubu çocukların ağız-diş sağlığı durumlarının değerlendirilmesi. GÜ Diş Hek Fak Derg 2000;17:1-6.

20. Liompart G, Marin GH, Silberman M, Merlo I, Zurriga $O$. Oral health in 6-year-old schoolchildren from Berisso, Argentina:Falling far short of WHO goals. Med Oral Patol Cir Bucal 2010;15:101-5.

21. Wei SHY, Holm A-K, Tong LSM, Yuen SWH. Dental caries prevalance and related factors in 5year-old children in Hong Kong. Pediatric Dent 1993; 16:116-9.

22. Saydam G, Oktay İ, Möller. Turkiyede Ağız Diş Sağıı̆ı Durum Analizi. Dünya Sağlık Örgütü Avrupa Bölgesi-Sağlık Bakanlığı, Ankara, 1991.

23. Eronat $N$, Ertuğrul $F$, Uğur ZA, Önçağ Ö, Köse $T$. İzmir Bornova'da sosyo-ekonomik düzey ile ağız diş sağlığı durumunun 7 ve 12 yaş grubu çocuklarda değerlendirilmesi. H Ü Diş Hek Fak Derg 1997;21:46-51.

24. Kuvvetli SS, Cildir SK, Ergeneli S, Sandallı N. Prevalance of noncavitated and cavitated carious lesions in a group of 5-year-old Turkish children in Kadıköy, İstanbul. J Dent Child (Chic) 2008; 75:158-163.

25. Namal N, Yüceokur AA, Can G. Significant caries index values and related factors in 5-6-year-old children in İstanbul, Turkey. East Mediterr Health ] 2009;15:178-184.

26. Hjern A, Grindefjord $M$, Sundberg $H$, Rosen $M$. Social inequality in oral health and use of dental care in Sweden. Community Dent Oral Epidemiol 2001;29:167-74.

27. Thomson WM, Poulton R, Kruger E, Boyd D. Socio-economic and behavioural risk factors for tooth loss from age 18 to 26 among participants in the Dunedin multidisciplinary health and development study. Caries Res 2000;34:361-6. 
28. Mothupi KA, Nocobo CB, Yengopal V. Prevalance of early childhood caries among preschool children in Johannesburg, South Africa. J Dent Child (Chic) 2016 ;83: 83-7.

29. Marthaler T, Menghini G, Steiner M. Use of the Significant Caries Index in quantifying the changes in caries in Switzerland from 1964 to 2000. Community Dent Oral Epidemiol 2005; 33: 159-66.

30. Calado R, Ferreira CS, Nogueira P, Melo P. Caries prevalence and treatment needs in young people in Portugal:the third national study. Community Dent Health 2017; 34:107-111.

31. Giacaman RA, Bustos IP, Bazan P, Mario RJ. Oral health disparities among adolescents from urban and rural communities of central chile. Rural Remote Health 2018; 18: 4312-23.

32. Ferrazzano GF, Sangianantoni G, Cantile T, Ingenito A. Relationship between social and behavioural factors and caries experience in schoolchildren in Italy. Oral Helth Prev Dent 2016; 14: 55-61.

33. Campus G, Solinas G, Maida C, Castiglia P. The 'Significant Caries Index' (SiC): a critical approach. Oral Health Prev Dent 2003; 1: 171-8.

34. Nishi M, Stjernsward J, Carlsson P, Bratthall D. Caries experience of some countries and areas expressed by the significant Carirs Index. Community Dent Oral Epidemiol 2002; 30:296301.

\section{Yazışma Adresi}

Dr. Berna KUTER

Doktor Öğretim Üyesi

İZMİR DEMOKRASİ ÜNİVERSİTESİ

PEDODONTI ANABİLIM DALI

e-mail:berna.kuter@idu.edu.tr 